\title{
Knowledge Management of Best Practices in a Collaborative Environment
}

\author{
Amal Al-Rasheed \\ Information Systems \\ Princess Nora University (PNU) \\ Riyadh, Saudi Arabia
}

\author{
Jawad Berri \\ Information Systems \\ King Saud University (KSU) \\ Riyadh, Saudi Arabia
}

\begin{abstract}
Identifying and sharing best practices in a domain means duplicating successes, which help people, learn from each other and reuse proven practices. Successful sharing of best practices can be accomplished by establishing a collaborative environment where users, experts and communities can interact and cooperate. A detailed review of previous research in best practice knowledge management shows that existing models have focused on developing methodologies to manage best practices but most of them did not propose solutions towards the development of full-fledge systems that make use of technologies to allow effective sharing and reuse of best practices. This paper presents a life cycle model to manage expertise for communities of practice. The proposed model is implemented in the education field as a knowledge management system that promotes and values user's contributions. We focus on the case of best teaching practice (BTP) as they develop instructor's abilities and improve overall instruction quality in higher education. For this purpose, we developed a computer environment including a knowledge management system and a web portal to assist instructors in higher education in the creation, sharing and application of BTPs.
\end{abstract}

Keywords-Best practice; knowledge management system; knowledge sharing; higher education; life cycle; portal

\section{INTRODUCTION}

Knowledge is a key asset in the information age. Knowledge management can be seen as the set of activities that involve capturing all the best practices and knowledge that people acquire and storing them in a computer system in the hope that one day it will be useful [1]. The term "best practice" refers to "those practices that produce superior results; selected by a systematic process; and judged as exemplary, good, or successfully demonstrated" [2]. The purpose of managing BP is to learn from others' best or most successful performances and adjusting their approach to meet specific needs [3]. In fact, deciding what is "best" is not easy. Best practices can vary over time, as new evidence and new possibilities arise, and from place to place, depending on available resources and infrastructure [4].

People who share common interests connect with each other by participating in a community. Thus, successful sharing of BP can be accomplished by establishing a well-motivated community $[5,6]$. A common definition of community emerged as a group of people with varied characteristics who share common perspectives, and engage in joint action in geographical location [7]. The concept of community has changed since the advent of the Internet. Now, individuals who share common interests can meet virtually in an online community without geographical restriction [8]. The great majority of virtual communities depend on Web-based environments to connect, collaborate, communicate and contribute to community activities $[9,10]$. A community's specific purpose and goals inform the appropriate activities and technologies that should support it.

In this paper, we propose a BP development life cycle that specifies the required steps for engineering $\mathrm{BP}$ and integrates the Web technologies that are essential for their implementation. Application of the proposed model is illustrated by reference to the education field - specifically, the use of best teaching practices (BTP) to develop instructor abilities and improve overall learning in higher education.

The rest of this paper is structured as follows. The next section explores the concept of BP, and we then introduce our proposal for a BP life cycle model. The model is illustrated by applying it to the education field, and the paper ends with a brief summary and conclusion.

\section{Best Practice IN KNOWLEDGe Management}

\section{A. What is a "best practice"?}

A best practice is generally defined as "an improvement in a particular process, approach, technique, or subject matter knowledge that is good enough to replace an existing practice and general enough to merit being disseminated widely throughout an organization" [11]. The term is used in many areas that include health, education, government administration and project management [12]. Some people favor the term "good practice" on the grounds that while there are many good practices, it is difficult to achieve consensus on a single "best practice". An acceptable alternative definition of BP, then, is "one that has been proven to work well and give good results, and is therefore recommended as a model" [13, 14].

It is important to note that most BP-related knowledge is tacit; this can be difficult to document because it is held in people's heads and may therefore be less easily expressed [15]. For this reason, BP-related programs necessarily include two key components: explicit knowledge and tacit knowledge. While sharing of explicit knowledge connects people with information (e.g., in a BP database), tacit knowledge sharing connects people with other people (e.g., through communities of practice). These methods complement each other; while a database enables users to search for $\mathrm{BP}$, the best way of 
sharing BP is by joining communities and interacting with individuals who have previously used that BP [16].

\section{B. The benefits of sharing BPS}

Replicating a success in one part of the organization across all others is one of the best ways to improve performance [17, 18]. Sharing internal BPs is particularly helpful when an organization comprises multiple units, enabling individuals doing similar work to gain from each other [19]. In organizations, identifying BPs enhances learning and reuse of proven practices among staff members. Additionally, successful sharing of BPs enables an organization to i) improve the quality of services provided; ii) avoid duplication of effort or "reinventing the wheel"; iii) reduce the need to redo work; and iv) save money through increased efficiency and productivity [20].

\section{MANAGing Best PRACTICES}

The integration of BPs within an organization is not a straightforward task and is generally implemented as a life cycle. A life cycle introduces specific steps for understanding how organizational knowledge is processed during its useful lifespan

\section{A. Previous work}

A review of the relevant literature identified a number of models of BP. The "pull" model as a mechanism for BP transfer was proposed by Pickard and Golden (1995). Its basic idea was to establish a technology transfer agent and then to assign a technology transfer mechanism to users in that industry sector by means of interviews and workshops. The main characteristic of the "pull" model is a high level of faceto-face communication between technology suppliers and industry executives [21].

Ashton (1998) was among the first to address the need for a "coherent and practical framework for BP," which he sought to create by identifying a set of process phases [22]. He found that the organizations under consideration already had a defined BP management process. Ashton noted the importance of technology in improving the corporate $\mathrm{BP}$ process, and of measuring it against credible frameworks.

Jarrar \& Zairi (2000) made a significant contribution by constructing a framework based on success factors derived from the experiences of various organizations [2]. As well as the framework, they emphasized that advances in IT would be the main factor to impact benchmarking in the future.

In another important study, Signal (2006) constructed a BP transfer process consisting of five main steps [18]. The first of these was to determine critical processes and factors relating to quality, safety and productivity. The next step was to prepare drafts for stakeholders and process experts, detailing BP for the processes in question. The drafts would then be reviewed before finally accepting and publishing the reviewed drafts as BP benchmarks.

Another framework in [23] suggested six major steps for identifying and sharing BPs. The general aim of this approach was to define the significant features of a BP, identifying the relevant experts, concluding overall guidelines, diffusing basic knowledge and encouraging subject matter experts to apply and adjust the practices in alignment with the new context.

\section{B. The BP Cycle Model}

While each of the above frameworks clearly introduced valuable new elements to the BP process, these earlier approaches have the following limitations:

- Many frameworks applied to traditional communities in which members generally meet face-to-face; current technologies extend this concept by overriding geographical and social boundaries, removing language barriers and bringing together experts from around the world [24].

- Earlier approaches focused on acquiring explicit BP through phases such as identify, find, search and discover. However, most BP knowledge is tacit and requires specific mechanisms to capture it. In practice, tacit knowledge is hard to acquire because it is difficult to communicate to others. Consequently, the creation of new knowledge entails the establishment of a virtual community and the fostering of social interactions among its members [25].

- Previous models focused on developing methodologies to manage BPs, but few have proposed solutions for the development of fully-fledged systems that exploit technologies for effective sharing and reuse of BPs.

Several important phases from earlier frameworks and life cycles have been adopted and incorporated in the construction of our simple, practical and comprehensive BP life cycle model for virtual communities. The aim of this model is to transform the individual knowledge residing in people's heads into public knowledge that is available to all practitioners. As illustrated in Fig. 1, the BP Cycle (BPC) model comprises six cyclical phases.

In some knowledge management cycles, the identify and create phases are grouped together; some authors have argued for this approach on grounds of the clear overlap between the two [26]. In our opinion, all practices have to pass through these as two distinct phases. When a $\mathrm{BP}$ request is made, the searcher must first identify the appropriate knowledge if it exists in-house; if not, the BP must be created or acquired. Even if the required knowledge is found, in most cases it will need to be tailored for each specific situation by auditing existing BPs [27]. 


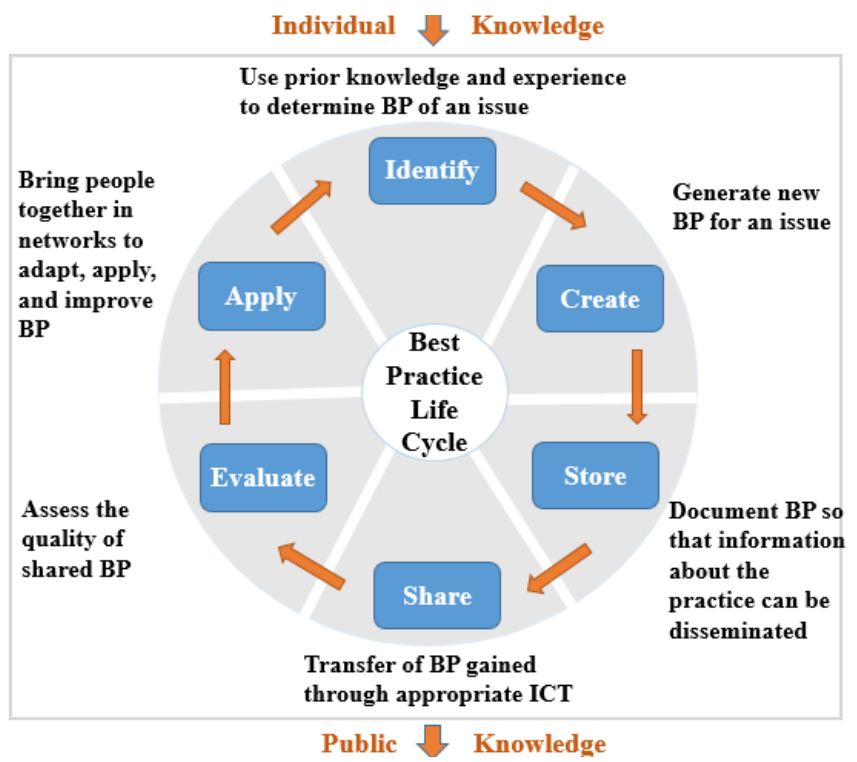

Fig. 1. The BP Cycle (BPC) Model

The key steps of the BPC model are as follows.

\section{1) Identify}

This phase is about searching and finding best practices wherever they are. However, finding best practices is not easy. It involve using prior knowledge and experience to determine best ideas/practices of an issue. Identifying BPs focuses on explicit knowledge that can be found, codified and formalized, in sources such as literature reviews, databases, knowledge repositories and training courses [2]. Actually, this phase starts by looking at what areas or issues need attention, considering where one can really add value, and determining who will benefit most from better knowledge and understanding of good practices $[2,23]$. Along with effectively finding best practices, the identify phase implicates analyzing and assessing knowledge based on specific evaluation criteria [26].

\section{2) Create}

This phase involves generating new good practices for an issue if none found through searching during the identify phase. New best practices may also need to be created if existing ones only partially satisfy knowledge needs [26]. Much of best practice knowledge is tacit and not always easy to document [16]. Therefore, this phase implicate using some tools and technologies for elicitation tacit knowledge. There are several ways to create good practices. One is to examine individuals and groups that provide excellent results and therefore expected to be using good practices. Having discovered these, one will then need to recognize what parts of their whole method or approach represent good practice. However, other approaches exist too such as communities of practice and interviews. In fact, knowledge workers learn from their experience. They may create new knowledge as a response to the "failures or successes" of previous phases. This way, feedback is used to create new knowledge that has been contextualized [1].

3) Store

In this phase, the codified best practices are stored physically, which entails using technology to build knowledge repository. Some examples of technology include intranets; databases; knowledge portals; archives of knowledge; and information systems [28]. The repository cannot be a random collection of best practices regardless of their individual and collective value. Best practices must be stored in a structured way that allows them to be manipulated, retrieved, and shared efficiently. Common related activities include tagging, annotating, archiving, classifying, and improving search and retrieval needs [26]. Moreover, to store best practices effectively, their descriptions are commonly kept in a database in a standard format. A typical template might contain the following information about best practice: title, profile, context, resources, description, lessons learned, links to resources, and tools and techniques [23].

\section{4) Share}

This phase represents the core of 'best practice life cycle' since the primary goal of the process is to make the contributed best practices available for individuals to take advantage of them. 'Share' entails internal and external collaboration and communication between individuals, along with extensive use of technology for the dissemination of knowledge. An explicit and flexible network of expertise (as in a community of practice) enhances collaboration and can strongly assist the sharing of BPs [26]. It is also important to choose the optimum mix of technologies and dissemination channels [11]. Some of the most common technologies used to share knowledge assets are content management systems, communication and collaboration technologies, blogs, social media and websites [11].

\section{5) Evaluate}

A practice is judged to be good if there is an obvious link between what is practiced and the desired outcome [23]. In most cases, assessing what we believe a good practice is essential. Meantime, deciding on the value of different ideas in relation to the required intention and the outcome in question. The evaluate phase is context-based and dependent on the specific situation and individual or group, who must validate BPs based on their experience [2]. Such assessments of validity are based on two questions: Is a practice perceived as BP really best, and does the transferred BP perform as required? [2]. A common approach is to ask a panel of peer reviewers to evaluate a potentially good practice [29]. Moreover, some organizations tackle the validity issue through iterative process of workshops, guidelines featuring assessment, feedback and measurable improvements. These ensure validity through assessment and feedback, determine if the best practices have produced measurable improvement, and consider whether it is recognized by internal and external sources. There is no doubt that more extensive use of information technology and social networks offers less expensive methods for assessing information and knowledge in general. Such methods depend on community interaction and feedback by motivating users to add their ratings and comments.

\section{6) Apply}

The importance of 'apply' lies in the fact that it is the motive for the evaluation and creation of more knowledge. In this phase, people is brought together in networks to adapt, apply, and improve best practices. Once shared, BPs can be activated and their value extracted and applied to solve 
problems, make decisions, improve efficiency or promote innovative thinking [26]. This phase is also key to internalizing tacit forms of knowledge and for that reason is sometimes called "learning-by-doing" [11]. Some of the more common activities in the apply phase include developing communities of practice, locating experts and running coaching workshops and tutorials. The technologies employed in these activities may include knowledge repositories, search engines and communication and collaboration technologies [28]. It is important to note that all of the KM efforts have been in vain unless this phase is performed successfully [26]; application of knowledge is the key success of any knowledge management system (KMS).

Surrounding the process, and helping it, what we call the enablers technology, culture, leadership, and measures. We have to address the aspects of the infrastructure and the environment of the organization in order to enable the transfer process to have a change in work. One reason that the internal transfer is so difficult is that these enablers have been poorly understood and were rarely addressed in earlier attempts [17].

\section{Managing Best Practices}

In conducting this research, we have focused on best teaching practices (BTP) that develop instructor abilities and improve overall learning in higher education. BTP represents instructors' expertise as accumulated while teaching and can be defined as a "method that clearly adds value in teaching a course by saving time or clarifying a concept." BTP is acquired through experience; it has been applied many times and has been proven to work well, gives good results and can therefore be recommended as a model. Identifying, sharing and reusing BTPs means duplicating successes to help instructors to learn from each other, resulting in innovative ideas for improving the effectiveness of teaching and learning. BTP is a key influence on student learning, and as such, it is a desired outcome and an essential objective of higher educational institutions. University instructors often struggle to adhere to the principles of BTP in attempting to provide the best learning experience for their students $[30,31]$.

In the e-learning field, most efforts have focused on the expression and transmission of course content to learners, with very little attention given to transmitting instructors' expertise or enabling instructors to communicate their methods of teaching and delivering knowledge. It is essential to create and provide an appropriate environment and technical conditions for instructors to create, transfer, share and apply knowledge effectively [8]. Clearly, this should include exploiting, improving and managing the existing BP knowledge of university instructors to enhance the overall development of teaching and scientific research levels in higher education.

\section{APPLICATION OF THE PROPOSED BPC MODEL}

This section illustrates the use of the proposed cycle in the context of BTP.

\section{A. Identify and Create BTP}

In the proposed model, the process of identification and creation of BP knowledge entails seven steps (Fig. 2).

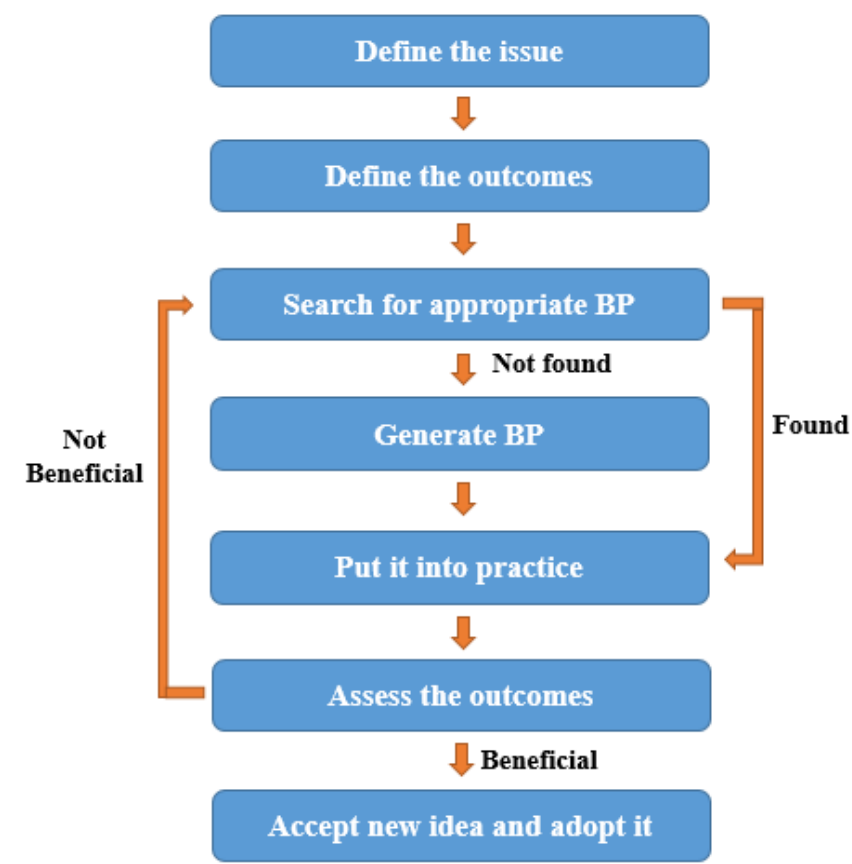

Fig. 2. Steps for identification and creation of BP knowledge

\section{1) Define the issue}

The need for good/best practice stems from the existence of a difficulty facing an instructor in teaching a specific topic. Defining clear objectives is key to the success of identifying and creating BP. Defining the issue precisely eases the process of finding resources that match the intended objective.

\section{2) Define the outcomes}

The instructor must define the outcomes they intend to achieve in applying a BP. The selected BP should aim at accomplishing the predefined outcomes. However, defining outcomes guide the instructor in developing appropriate learning experiences for students, and play a major role in assessment.

\section{3) Search for appropriate BP}

Once the instructor has defined what they are looking for, they must establish what is available. When faced with a number of relevant BP choices, the next step is to minimize the search results by eliminating those that are unsuitable for the students in question or do not address the intended outcomes. Instructors can find BPs using:

- The Internet. The Internet is undoubtedly the largest single source of best practice information available. Anyone with good search skills can find nearly anything.

- Networking. Contacting knowledgeable people in the same field to find out what they know is useful in inspiring us and enriching our information.

- Libraries. Libraries are a great source and helpful in finding what we are looking for. Now, we can find many journals and individual journal articles on the Internet as well. 
- Communities. Clearly, members of the same community may know of successful practices or initiatives similar to the one that we need.

\section{4) Generate $B P$}

If no relevant $\mathrm{BP}$ is found by searching or if those found only partially satisfy knowledge needs, the instructor must generate a new BP. As much BP knowledge is tacit and may be difficult to generate and document, the instructor may draw on prior experience or consult with other academics in the same field to benefit from their successful practices.

\section{5) Put it into practice}

Knowledge and new ideas are of no value unless we put them into practice. On finding or generating BPs, the instructor should apply them in teaching to test their applicability.

\section{6) Assess the outcomes}

Outcome assessment aims to measure the success and applicability of new ideas. We may consider new ideas to be good or best practices if they prove their success following implementation. The instructor should compare the results against intended outcomes and then use the resulting information to improve the quality of the new ideas. If the issue remains unresolved, return to the starting point.

\section{7) Accept new ideas and adopt them}

Once a new idea has met expectations, it may be regarded as a good or best practice and applied in teaching. However, even a practice that is considered good or best may be further developed, and one should always remain open to possible improvements.

\section{B. Store BTP}

Collected BPs can usefully be stored in an accessible knowledge base for future reuse. Today, we can access extensive knowledge of great value. The challenge is not the creation of new knowledge; the problem is that existing knowledge is often badly organized and almost inaccessible.

The issue, then, is how BP information can be organized and classified in a knowledge base to enable users to more easily find and share what they need. Organizing and classifying BP knowledge involves its formal specification, which defines the attributes of knowledge and how it will be represented. Defining knowledge attributes is the first step toward designing a knowledge management system.

Knowledge attributes describe the artifacts exchanged and shared by users to refer to information obtained by the knowledge creator. In practice, this means that experts provide information manually, and because these attributes cover a wide range of information, it is difficult to define precisely its scope. The information gathered about best teaching practices falls into two main categories: knowledge object and knowledge creator or consumer.

\section{1) Knowledge object ( $\mathrm{KO})$}

The many definitions of knowledge to be learned include terms such as "knowledge objects" $\lceil 32\rceil$, "educational software components" [33], "sharable content object" [34], "courseware unit" [35], "educational objects" [36] and "learning object" [37]. In considering best teaching practices, the broadly used concept of KO [32] seems most convenient. According to Merrill (1998), a KO is "a precise way to describe the subject matter content or knowledge to be taught" and a "way to organize a data base (knowledge base) of content resources (text, audio, video, and graphics)". The components of KOs should not be confined to a particular subject area; the same components can be used to represent knowledge in different areas (e.g., science, mathematics, humanities, and technical skills).

In our research, we addressed learning object metadata, as these have much in common with teaching knowledge. In general, two popular approaches are used to describe metadata; the first collects metadata as records (implemented by the LOM standard) while the second considers metadata items individually (adopted by Dublin Core) [38]. For the purposes of a very general model and to ensure compatibility with existing platforms, we have adopted the second approach. However, as Dublin Core standards are used to describe the "learning object," we have added new attributes to fit with KO description and the BP process. Relevant attributes of KOs include keywords, material type, course name, course level, discipline, sub-discipline, attachment and usage. Table 1 illustrates the main attributes of the $\mathrm{KO}$ and provides a detailed description of those attributes.

TABLE I. DESCRIPTION OF ATTRIBUTES OF KO

\begin{tabular}{|l|l|}
\hline Attribute & Description \\
\hline Title $*$ & Name of KO as given by its creator \\
\hline Description $*$ & Textual description of KO content \\
\hline Keywords & Tags describing the KO topic \\
\hline BP type & $\begin{array}{l}\text { Classification of KO by its specific use or } \\
\text { application (e.g., teaching experience, lessons } \\
\text { learned, user guide) }\end{array}$ \\
\hline BP (Subject) $*$ & Detailed description of the topic \\
\hline Creator $*$ & Person responsible for making the content \\
\hline Discipline & $\begin{array}{l}\text { Branch of knowledge to which the KO belongs } \\
\text { (e.g., computer science, engineering, mathematics) }\end{array}$ \\
\hline Sub-discipline & Field of specialized study within a discipline \\
\hline Course name & Name of course that includes the KO topic \\
\hline Level of course & Study level of course that includes the KO topic \\
\hline Coverage * & Time, culture, or region to which the KO applies \\
\hline Language * & Primary language used within the KO \\
\hline Attachment & Related file/s (e.g., MS word, PowerPoint, PDF) \\
\hline Media format * & $\begin{array}{l}\text { Technical type of the learning object (image, audio, } \\
\text { video) }\end{array}$ \\
\hline Source * & $\begin{array}{l}\text { String used to access the KO (e.g., Universal } \\
\text { Resource Locator) }\end{array}$ \\
\hline Publisher * & Entity responsible for making the content available \\
\hline Contributor * & Person responsible for contributing to the content \\
\hline Date * & Date of creation or availability of the content \\
\hline Identifier * & Referring to the KO \\
\hline Usage & Flag indicating the KO's use in teaching \\
\hline Rights * & Terms of use of the KO \\
\hline Source: Dublin Core Standards \\
\hline
\end{tabular}




\section{2) Knowledge creator/consumer}

The knowledge creator is the person responsible for contributing new knowledge based on their experience in a particular field; the knowledge consumer uses the new knowledge to supplement their existing knowledge. The instructor's information should be taken into account to facilitate knowledge sharing and dissemination. Table 2 details the main attributes of the knowledge creator/consumer.

TABLE II. DESCRIPTION OF ATTRIBUTES OF KNOWLEDGE CREATOR/ CONSUMER

\begin{tabular}{|l|l|l|}
\hline Category & Attribute & Description \\
\hline \multirow{4}{*}{ General } & First Name & Instructor's first name \\
\cline { 2 - 3 } & Last Name & Instructor's last name \\
\cline { 2 - 3 } & ID & Unique label that identifies the instructor \\
\cline { 2 - 3 } & Ehoto & Personal photo \\
\cline { 2 - 3 } & Website & Instructor's e-mail \\
\cline { 2 - 3 } & Bio & Instructor's website address \\
\hline \multirow{5}{*}{ Profession } & $\begin{array}{l}\text { Detailed description of instructor's life, } \\
\text { including education, work, relationships, } \\
\text { and experience }\end{array}$ \\
\cline { 2 - 4 } & Title & e.g., PhD, professor, engineer \\
\cline { 2 - 4 } & Educational level & Instructor's degree \\
\cline { 2 - 4 } & Institution & Institution that the instructor belongs to \\
\cline { 2 - 4 } & Department & Department that the instructor belongs to \\
\cline { 2 - 4 } & Discipline & $\begin{array}{l}\text { Branch of knowledge studied by the } \\
\text { instructor in HE education }\end{array}$ \\
\cline { 2 - 4 } & Sub-discipline & Field of specialized study within \\
\hline & Area of expertise & List of the instructor's teaching areas \\
\hline & Courses & List of courses that the instructor teaches \\
\hline
\end{tabular}

Fig. 3 provides a detailed example of information about BTP stored in the knowledge base.

\section{Share BTP}

Instructors should be able to express their teaching innovations. The main challenge is to persuade instructors to share their expertise and to interact with their peers. As mentioned above, constructing the knowledge base is the first step toward designing a knowledge management system to support the knowledge base and to facilitate sharing and dissemination of existing knowledge.

To that end, we have developed a KMS that supports and stimulates instructors, educators and communities to express and share their expertise. The proposed system is based on two key principles: i) free-user contribution, which means that any proposed contribution by any instructor is welcome and there is no control or moderation of contributions by any instructor; ii) peer scoring of knowledge, which means that any contribution will be scored by other users, achieving a high score if it is frequently reused, liked and positively commented. The purpose of these two principles is to encourage voluntary contributions and to ensure fair evaluation and feedback from specialists. The proposed system promotes parity of interaction, where users work in a collaborative environment to promote co-construction and sharing of knowledge resources, with direct advantages for participants.

The KMS was implemented as a knowledge portal using Drupal (drupal.org), which is a free community-supported content management system for creating, organizing, presenting and managing a website [39]. Drupal offers more flexibility for the programmer than other existing content management systems to develop user specific applications. The portal runs on a digital platform that supports Apache, PHP and MySQL to store content and settings.

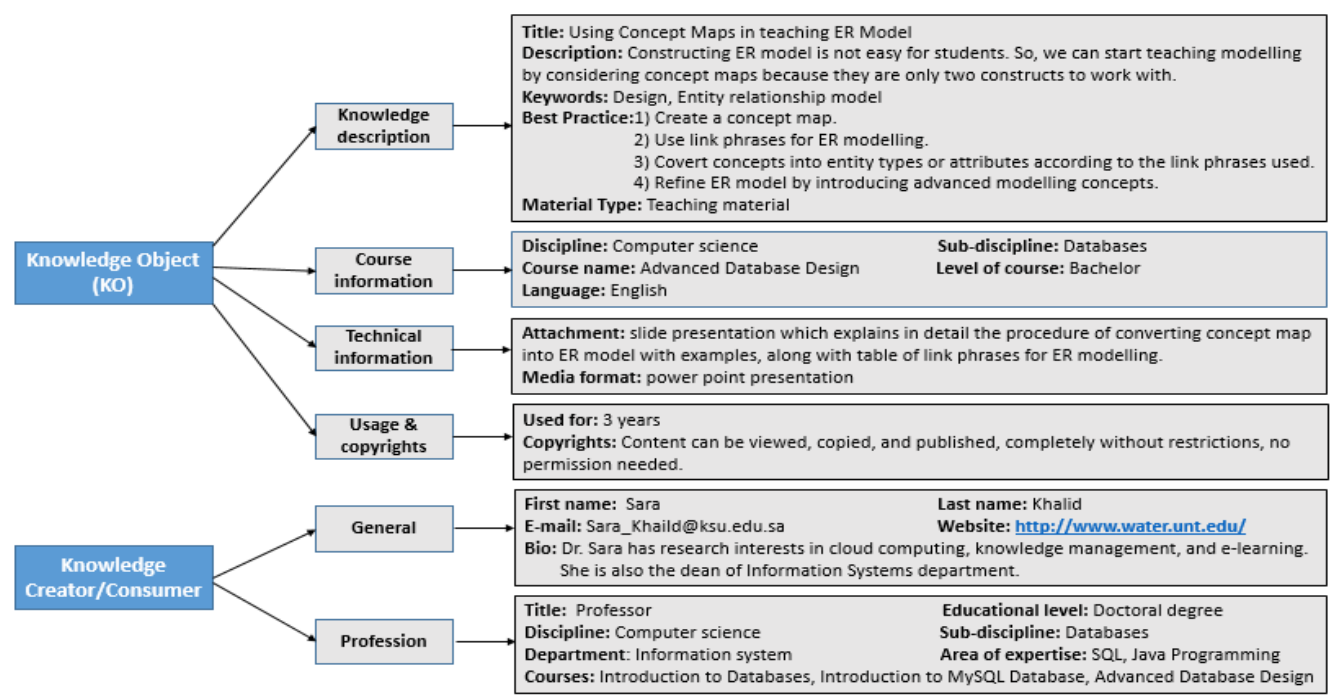

Fig. 3. Example of stored information about BTP

The knowledge portal maintains a dynamic client-side graphical user interface that handles all user requests and collaborative activities. It facilitates knowledge acquisition, discovery and sharing by enabling instructors to publish knowledge, work collaboratively, share ideas and store knowledge resources in a searchable knowledge base. The knowledge portal also authenticates users and manages the rights and authorizations for each user within a more broadly defined university community. Fig. 4 illustrates the knowledge portal homepage. 


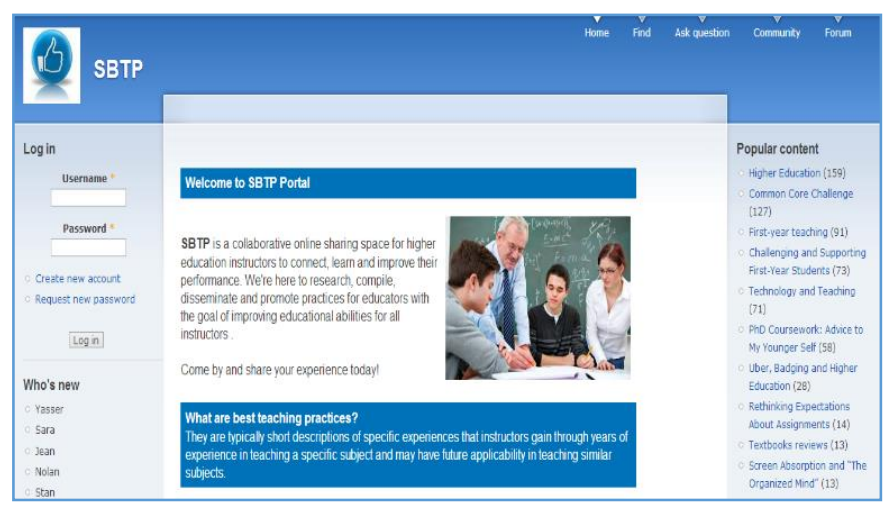

Fig. 4. Knowledge portal homepage

In the portal, many techniques were adopted to encourage the community to become more involved and self-supporting. Discussion forums were set up to foster member engagement and sharing of expertise and information. Members from the same discipline share a dedicated forum; these currently include computer science, mathematics and engineering. The portal also concentrates on capturing and sharing knowhow expertise through blogging, where instructors with the same interest form groups to contribute and post their experiences. Unlike forums, blogs are established on the basis of interests rather than disciplines. A list of communities is illustrated in Fig. 5.

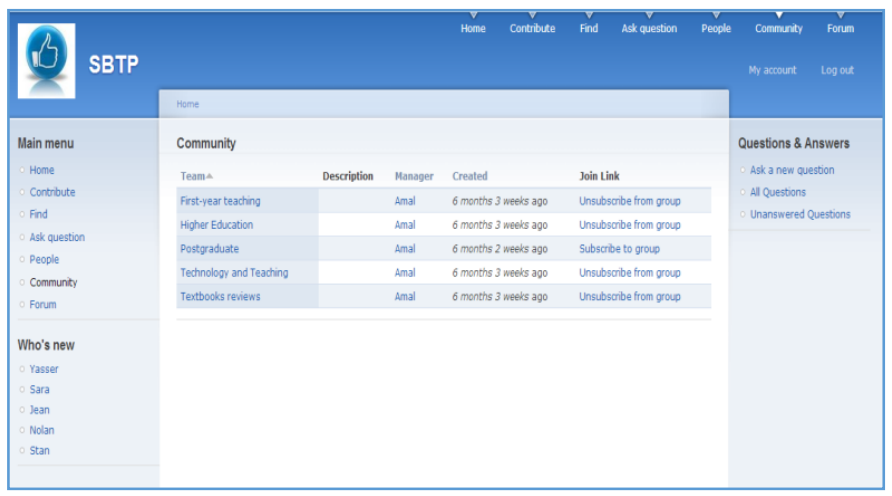

Fig. 5. List of communities

\section{Evaluate BTP}

The increasing volume of knowledge makes it more difficult to access target knowledge. Most searches of knowledge bases return a large number of KOs without any indication of quality or value, making it difficult for users to identify results that meet their needs. This creates an urgent need to find new ways of evaluating and presenting KOs ranked by quality and value. Existing evaluation tools are costly and time-consuming because they are qualitative and rely on expert review $[40,41]$, and there is a need for new tools that automatically evaluate and provide an assessment of knowledge resources, based on a number of specified parameters. Evaluation tools involve collaboration among multiple users, in which participants converge on accurate evaluations through a combination of user ratings, comments and views. For that reason, the proposed system automatically evaluates knowledge, assesses its quality, recommends the qualified experience in terms of various measures and assigns a quantitative score for overall rating of KOs, allowing search results to be re-ranked according to the quality score.

The system adopts an extrinsic motivator, based on a reward system for scoring BTPs. The scoring function combines three weighted component measures: i) author score, measuring the relevance of an author in terms of their contribution to the system; ii) feedback, representing the degree of satisfaction of other users who have shared and reused the BTP; and iii) comments, measuring the feedback of users who did not use the BTP. The scoring function is a reward system that measures both contributor importance and the reputation of the BTP. When community members interact with a specific BTP as users or simply by adding comments, they automatically affect its rating. Earning reputation points by contributing knowledge can encourage an individual to become more involved when they recognize these benefits.

\section{E. Apply BTP}

The key to the success of any KMS is the reuse and application of stored knowledge. When that knowledge is used, it is refined and developed, and additional knowledge is created; the knowledge base is enriched; and the cycle repeats itself. Belief in the effectiveness of BPs is a prerequisite for replication; without this, the system will not succeed, even if everything else is in order. It follows that members must be persuaded that the adoption, use and implementation of BPs is feasible. This can be achieved by educating the community about the importance of BPs and by stimulating their commitment to use them. To do so, our system provides person-to-person linkage to support the application and use of tacit knowledge. Additionally, links connect members to experts who have identified and used the BP for further information. This technique helps to improve the transfer of tacit knowledge and social community practices among members.

\section{CONCLUSION}

Knowledge management (KM) is concerned with finding ways to make tacit knowledge explicit through documenting best practice to enhance knowledge sharing through human to human collaboration. Consequently, the best practice system is recognized as one of the main KM solutions in many KM literature or research. The first contribution of this paper was the construction of a practical and comprehensive best practice life cycle model for communities of practice which comprises six phases: identify create, store, share, evaluate, and apply. This model is based on studying earlier best practice processes and life cycles in the literature. The second contribution of this research is the development of a system that allows communities of practice who share common interests to build a collaborative environment to create, disseminate and apply best teaching practices in teaching. Creating an online community where university instructors would freely share their innovative teaching experiences can leverage noticeably the quality of instruction for the benefit of students and instructors. The implemented system has been used by a community of instructors at our university to interact, collaborate and share BPs within their fields of interest. The results of this experience are very promising and encourage further development of this research. 
Future work will investigate the possibility of coupling our system with the learning management system (LMS) currently used by the university's instructors.

This will allow instructors to input BPTs automatically from the LMS in an integrated learning environment that fosters more intuitive exchange and collaboration.

\section{REFERENCES}

[1] R. Magnier-Watanabe, C. Benton, a. countries and D. Senoo, "A study of knowledge management enablers across countries," Knowledge Management Research \& Practice, vol. 9, p. 17-28, 2011.

[2] Y. Jarrar and M. Zairi, "Best practice transfer for future competitiveness: a study of best practices," TOTAL QUALITY MANAGEMENT,, pp. VOL. 11, NO. 4/5\&6, p.734- 740, 2000(a).

[3] R. Cox and C. Cunial, "Best Practice Within Australian Food Service, a Case Study: Customer satisfaction with red meat products," Australian Agribusiness Review, p. 14 (paper 13), 2006.

[4] Y. F. Jarrar and M. Zairi, "Internal Transfer of Best Practice for Performance Excellence: A Global Survey," Benchmarking: An International Journal, pp. Vol 7, No 4, pp. 239-246, 2000(b).

[5] F. Henri and B. Pudelko, "Understanding and analysing activity and learning in virtual communities," Journal of Computer Assisted Learning (2003), pp. vol. 19, pp. 474-487, 2003.

[6] R. Ramasami, Knowledge Management, Lulu.com, 2011.

[7] K. M. MacQueen, E. McLellan, D. S. Metzger, S. Kegeles, R. P. Strauss, R. Scotti, L. Blanchard and R. T. Trotter, "What is community? An evidence-based definition for participatory public health," American Journal of Public Health, pp. vol. 91, no. 12, pp. 1929-1938, 20, 2001.

[8] J. Hautala, "International academic knowledge creation and ba. A case study from Finland," Knowledge Management Research \& Practice, vol. 9, p. 4-16, 2011.

[9] D. Cambridge, S. Kaplan and V. Suter, "Community of Practice Design Guide," Communities, pp. 1-8, 2005.

[10] S. Dani1, J. A. Harding, K. Case, R. I. M. Young, S. Cochrane, J. Gao and D. Baxter, "A Methodology for Best Practice Knowledge Management," Proceedings of the Institution of Mechanical Engineers, part B: Journal of Engineering Manufacture, , pp. 220 (10), pp. 1717$1728,2006$.

[11] K. Dalkir, Knowledge Management in Theory and Practice, Oxford: Elsiver, 2013.

[12] WHO, "Guide for Documenting and Sharing Best Practices in Health Programmes," World Health Organization, Regional Office for Africa, Brazzaville, 2008.

[13] FAO, "Good practices at FAO: Experience capitalization for continuous learning," Food and Agriculture Organization of the United Nations (FAO), 2013.

[14] S. G. Rabinowicz and V. Chinapah, "Good Practices in Pursuit of Sustainable Rural Transformation," Journal of Education and Research, pp. Vol. 4, No. 2, pp. 3-19, 2014.

[15] W. Reddy and S. McCarthy, "Sharing best practice," International Journal of Health Care Quality Assurance, pp. vol. 19, no.7, pp. 594$598,2006$.

[16] G. Servin, "ABC of Knowledge Management," NHS National Library for Health: Knowledge Management Specialist Library, 2005.

[17] C. O'dell and J. Grayson, "Identifying and Transferring Internal Best Practice," International Handbooks on Information Systems , pp. Volume 1, pp 601-622, 2004.

[18] P. Signal, "Best Practice Makes Perfect (2006)," Dairy Industries International, pp. Vol. 71, No. 2, pp. 32-35, 2006.

[19] M. Emanoil, S. Alexandra and C. L. Mihaela, "Knowledge workers drivers to organizational performance in a knowledge-based economy," Mathematical Methods in Engineering and Economics , pp. 150-154, 2014.
[20] M. D'Adamo and A. Kols, "A Tool for Sharing Internal Best Practices," The INFO Project. United States Agency for International Development (USAID), 2005.

[21] Z. A. Hamid and K. A. M. Kamar, "Modernising the Malaysian Construction Industry," in in Proceedings: W089 - Special Track 18th CIB World Building Congress (combined with TG71 and TG73), Salford, UK, 2010.

[22] C. Ashton, Managing Best practices, London: Business Intelligence, 1998.

[23] D. Skyrme, "Best Practices in Best Practices. K-Guide. Highclere, England, David Skryme Associates, June 2002.

[24] E. Wenger, "Communities of practice: A brief introduction.," 2007.

[25] M. Massaro, M. Pitts, F. Zanin and R. Bardy, "Knowledge Sharing, Control Mechanisms and Intellectual Liabilities in Knowledge-Intensive Firms," The Electronic Journal of Knowledge Management, pp. vol. 12, no. 2, pp. 110-121, 2014.

[26] M. M. Evans, K. Dalkir and C. Bidian, "A Holistic View of the Knowledge Life Cycle: The Knowledge Management Cycle (KMC) Model," Electronic Journal of Knowledge Management, p. Volume 12 Issue 2, 2014 .

[27] C. Janicot and S. Mignon, "Knowledge codification in audit and consulting firms: a conceptual and empirical approach," Knowledge Management Research \& Practice, vol. 10, p. 4-15, 2012.

[28] M. Evans and N. Ali, "Bridging knowledge management life cycle theory and practice," in Proceedings of the International Conference on Intellectual Capital, Knowledge Management and Organisational Learning - ICICKM, Washington University, Washington, DC, USA, 2013.

[29] O. Serrat, "Identifying and Sharing Good Practices," ADB Knowledge Solutions, 2008.

[30] L. Banachowski, AldonaDrabik and J. P. Nowacki, "Improving Process of Teaching Students by Means of Methods and Tools of Knowledge Management and e-Learning," International Journal of Innovation, Management and Technology, pp. Vol. 4, No. 6, 599-604, 2013.

[31] A. Essandoh, "Applying Knowledge Management in Teacher Evaluation Systems," PhD dissertation, WALDEN UNIVERSITY, p. 402 pages, 2013.

[32] M. D. Merrill, "Knowledge Objects," CBT Solutions, pp. 1-11, 1998.

[33] J. Roschelle, M. Koutlis, A. Repenning, J. Phillips, N. Jackiw and D. Suthers, "Developing Educational Software Components," in: Computer , pp. pp. 50-58, 1999.

[34] A. Panar and T. M. Shumaker, "Sharable Content Object Reference Model (SCORM), 4th edition," Advanced Distributed Learning, 2009.

[35] I. Grützner, D. Pfahl and G. Ruhe, "Systematic courseware development using an integrated engineering style method," in Proceedings of the World Congress "Networked Learning in a Global Environment: Challenges and Solutions for Virtual Education", Sliedrecht, 2002.

[36] N. Friesen, "What are Educational Objects?," Interactive Learning Environments, vol. vol. 9, no. no. 3, pp. pp. 219-230, 2001.

[37] D. A. Wiley, "Connecting learning objects to instructional design theory: A definition, a metaphor, and a taxonomy," In Wiley, D.A. (Ed.), The Instructional Use of Learning Objects, 2000.

[38] K. Cardinaels, E. Duval and H. Olivi', "A Formal Model of Learning Object Metadata," in Innovative Approaches for Learning and Knowledge Sharing, vol. Volume 4227, Berlin, Heidelberg, Springer, 2006, pp. pp 74-87.

[39] B. Melancon, J. Luisi and K. Negyesi, "The Definitive Guide to Drupal 7," Apress, 2011.

[40] N. Gupta, S. Chawla and R. K. Singla, "Proposed System of Automatic Evaluation of Learning Objects," International Journal of Scientific and Research Publications, pp. Volume 2, Issue 9, PP. 1-5, September 2012.

[41] L. Argote and P. Ingram, "Knowledge transfer: A Basis for Competitive Advantage in Firms," Organizational Behavior and Human Decision Processes, pp. 82.1: 150-169, 2000. 